\title{
Efecto de enmiendas orgánicas sobre las poblaciones microbianas de la rizosfera del cultivo de quinua (Chenopodium quinoa Willd.) en el altiplano Sur de Bolivia
}

\section{Effect of organic amendments on the microbial populations of the rhizosphere of quinoa cultivation}

(Chenopodium quinoa Willd.) in the South Altiplano of Bolivia

\author{
Paco-Pérez Victor*, Guzmán-Vega Gunnar-David
}

\begin{tabular}{l} 
Datos del Articulo \\
\hline \\
Universidad Técnica de Oruro-UTO. \\
Facultad de Ciencias Agrarias y Naturales \\
FCAN. Av. Dehene entre Román \\
Koslowky y León H. Loza (Ciudadela \\
Universitaria). Telf. 52 61645-52 62735. \\
Fax. (591-2) 52 61645. Oruro, Bolivia. \\
www.fcan.uto.edu.bo \\
*Dirección de contacto: \\
Victor Paco-Pérez \\
Facultad de Ciencias Agrarias y Naturales \\
FCAN. Av. Dehene entre Román \\
Koslowky y León H. Loza (Ciudadela \\
Universitaria). Telf. 52 61645-52 62735. \\
Fax. (591-2) 52 61645. Oruro, Bolivia. \\
Teléfono: +591 73720194. \\
E-mail: vicpaco@ hotmail.es \\
\end{tabular}

Palabras clave:

\section{Estiércol,}

extracto húmico,

quinua,

rizosfera,

microbiana.

J Selva Andina Biosph. 2019; 7(1):32-43.

\section{Historial del artículo.}

Recibido septiembre, 2018 Devuelto noviembre 2018 Aceptado febrero, 2019.

Disponible en línea, mayo 2019.

Editado por:

Selva Andina

Research Society

\section{Key words:}

Manure,

humic extract,

quinoa,

rhizosphere,

microbial.

\section{Resumen}

Las poblaciones microbianas en la rizósfera necesitan de MO como de los exudados de las plantas para su desarrollo. Los suelos de la región andina de Bolivia se caracterizan por contener bajos niveles en MO (<1.5\%). Por esta razón, es importante la incorporación de EO al suelo, lo cual favorecerá la relación entre microorganismo-planta. En el momento de la siembra, se aplica al suelo $430 \mathrm{~kg} / \mathrm{ha}$ de estiércol de camélido, extracto húmico y humita 15 fue utilizado $40 \mathrm{~L} / \mathrm{ha}$. Se recolectaron muestras de suelo rizosférico de la planta de quinua en los meses de octubre, enero y abril y fueron procesados por método seriado para evaluar la población total microbiana, cuantificar actinomicetos, bacterias y hongos y comparar su comportamiento. La población total mostró diferencias estadísticas significativas $(\mathrm{P}<0.05)$ en los cuatro tratamientos, donde el mes enero esta entre 3.73 a $3.54 \times 10^{6}$, abril de 3.70 a $3.53 \times 10^{6}$ y octubre de 3.40 a $3.39 \times 10^{6} \mathrm{UFC} / \mathrm{g}$ de suelo rizosférico. Los tres grupos microbianas mostraron mayor población en tratamiento aplicado con estiércol de camélido en los meses de enero y abril, donde las bacterias estan entre 1.44 a $1.43 \times 10^{6}$, actinomicetos de 1.23 a $1.20 \times 10^{5}$ y hongos de 1.07 a $1.06 \times 10^{4}$ UFC/g suelo rizosférico; el extracto húmico y humita 15 tienen poblaciones intermedias y el suelo sin aplicación con EO mostró población reducida en los tres meses. Los diferentes grupos microbianos mostraron similaridad en el incremento de poblaciones en los tres meses, pero las bacterias fue el que se expresaron con mayor número, seguido por actinomicetos y por último los hongos. Según el tipo de EO y el estado fenológico de la quinua evidencia que existe efectos favorables en el incremento de la población microbiana, facilita el hábitat en la rizosfera de la raíz y su variación está dado según las características propias del suelo y de su contenido de humedad, $\mathrm{pH}$ y de la temperatura.

(C) 2019. Journal of the Selva Andina Biosphere. Bolivia. Todos los derechos reservados.

\section{Abstract}

The microbial populations in the rhizosphere need MO as the exudates of the plants for their development. The soils of the Andean region of Bolivia are characterized by low levels of OM $(<1.5 \%)$. For this reason, the incorporation of EO into the soil is important, which will favor the relationship between microorganism-plant. At the time of sowing, $430 \mathrm{~kg} / \mathrm{ha}$ of camelid manure, humic extract and humita 15 was applied to the soil, $40 \mathrm{~L} / \mathrm{ha}$ was used. Samples of rhizospheric soil were collected from the quinoa plant in the months of October, January and April and were processed by serial method to evaluate the total microbial population, quantify actinomycetes, bacteria and fungi and compare their behavior. The total population showed significant statistical differences $(\mathrm{P}<0.05)$ in the four treatments, where the month January is between 3.73 to $3.54 \times 10^{6}$, April of 3.70 to $3.53 \times 10^{6}$ and October of 3.40 to $3.39 \times 10^{6} \mathrm{CFU} / \mathrm{g}$ of rhizospheric soil. The three microbial groups showed a greater population in treatment applied with camelid manure in the months of January and April, where the bacteria are between 1.44 to $1.43 \times 10^{6}$, actinomycetes from 1.23 to $1.20 \times 10^{5}$ and fungi from 1.07 to $1.06 \times 10^{4} \mathrm{CFU} / \mathrm{g}$ rhizospheric soil; the humic extract and humita 15 have intermediate populations and the soil without application with EO showed reduced population in the three months. The different microbial groups showed similarity in the increase of populations in the three months, but the bacteria was the one that was expressed with greater number, followed by actinomycetes and finally the fungi. According to the type of EO and the phenological status of the quinoa, there is evidence that there are favorable effects in the increase of the microbial population, it facilitates the habitat in the rhizosphere of the root and its variation is given according to the characteristics of the soil and its moisture content, $\mathrm{pH}$ and temperature.

(C) 2019. Journal of the Selva Andina Biosphere. Bolivia. All rights reserved. 


\section{Introducción}

Un ecosistema edáfico alberga un gran número de especies microbianas, tales como hongos, bacterias, actinomicetos, algas, entre otros que establecen relaciones intra e interespecíficas que contribuyen a las características propias del suelo ${ }^{1}$, los microorganismos cumplen un rol fundamental en el mantenimiento del suelo como ecosistema. ${ }^{2}$ Las diferentes prácticas de manejo del suelo afectan directamente a los parámetros fisicoquímicos y la normal actividad del microbiota. ${ }^{3}$

Las enmiendas orgánicas (EO) aportan al suelo materia orgánica (MO) que pueden mejorar propiedades físicas, químicas y microbiológicas, incrementando la fertilidad y favoreciendo la nutrición a las plantas. ${ }^{4-6}$ Además, es una manera segura y eficaz de recuperar nutrientes como nitrógeno $(\mathrm{N})$, fósforo (P) y otros elementos para las plantas. ${ }^{7}$

El término rizosfera se refiere al efecto de raíces de plantas sobre el suelo circundante en términos de mayor actividad microbiana por la liberación de MO por las raíces. ${ }^{8}$ Las bacterias son los organismos más abundantes en la rizosfera y son capaces de multiplicarse colonizando nichos ecológicos de raíz durante diversas etapas de su crecimiento. ${ }^{9,10}$

Las poblaciones microbianas tienen interacciones con raíces que dan lugar al desarrollo de un ambiente dinámico conocido como rizosfera. ${ }^{11}$ Algunos de estos organismos que son endofíticos, colonizan en la parte interna de los tejidos radicales e influyen en el crecimiento y en la protección vegetal. ${ }^{12}$

La quinua (Chenopodium quinoa Willd.), relativamente resistente a heladas y períodos de sequía, lo que facilita su cultivo en condiciones climáticas extremas del Altiplano Boliviano ${ }^{13,14}$, su crecimiento y desarrollo está determinado por su propia genética, con la fertilidad del suelo y por los factores ambientales $^{15,16}$, sin embargo, el monocultivo ha llevado a la desertificación de los suelos. Los objetivos del presente trabajo de investigación fueron i) evaluar la población total de microbiana existente en la rizosfera, ii) cuantificar actinomicetos, bacterias y hongos y iii) comparar su comportamiento en diferentes meses del desarrollo de la planta con la aplicación de diferentes EO.

\section{Materiales y métodos}

Ubicación geográfica. El ensayo se realizó en el Centro de Investigación de la Quinua (CIQ) dependiente de la Universidad Técnica de Oruro, que se encuentra ubicado en municipio de Salinas de Garci Mendoza, provincia Ladislao Cabrera al Sur del departamento de Oruro, geográficamente situado a 19³ '15' latitud Sur y 67\%40'27' longitud Oeste, a una distancia de $280 \mathrm{~km}$ de la ciudad de Oruro y a una altitud de $3.759 \mathrm{msnm}$.

Características agroecológicas. La zona corresponde al tipo semiárido con fríos extremos en invierno y con heladas de más de 200 días al año. El ciclo hidrológico está caracterizado por época seca y fría desde marzo a noviembre y la época lluviosa de diciembre a febrero. La temperatura media anual es de $8.9^{\circ} \mathrm{C}$, la máxima $18.7^{\circ} \mathrm{C}$ y la mínima de -2.9 ${ }^{\circ} \mathrm{C}$. La precipitación media anual es de 150 a 300 mm. ${ }^{17-19}$ Los problemas de erosión hídrica y eólica son frecuentes. La vegetación xerofítica es más acentuada; entre los que sobresalen es la Thola ( $\mathrm{Pa}$ restrephya sp.) y Paja brava (Festuca sp.). ${ }^{17-20}$

Características fisicoquímicas. Las muestras de suelo fueron enviadas al Laboratorio de Suelos y Aguas, Facultad de Ciencias Agrícolas y Pecuarias de la Universidad Mayor de San Simón. Los suelos expresan textura gruesa areno-francoso con contenidos importantes de grava, con pH 6.9 muy cercano a la neutralidad. 
Tabla 1 Características fisicoquímicas del suelo experimental de CIQ

\begin{tabular}{cccccccccccc}
\hline $\begin{array}{c}\text { Prof. } \\
\mathrm{cm}\end{array}$ & $\mathbf{A}$ & $\begin{array}{c}\mathbf{L} \\
\%\end{array}$ & $\mathbf{Y}$ & $\begin{array}{c}\text { Clase } \\
\text { textural }\end{array}$ & $\mathbf{p H}$ & $\begin{array}{c}\mathbf{D A P} \\
\mathrm{g} / \mathrm{cm}^{3}\end{array}$ & $\begin{array}{c}\mathbf{C E} \\
\mathrm{mmhos} / \mathrm{cm}\end{array}$ & $\begin{array}{c}\mathbf{K} \\
\mathrm{meq} / 100 \mathrm{~g}\end{array}$ & $\mathbf{M O}$ & $\mathbf{N t}$ & $\begin{array}{c}\mathbf{P} \\
\mathrm{ppm}\end{array}$ \\
\hline $5-25$ & 83 & 6 & 10 & $\mathrm{AF}$ & 6.9 & 1.39 & 0.75 & 0.98 & 1.43 & 0.07 & 9.19 \\
\hline
\end{tabular}

La conductividad eléctrica es de $0.75 \mathrm{mmhos} / \mathrm{cm}$ lo que expresa que es un suelo moderadamente alcalino con bajo contenido en MO de $1.43 \%$ y Nitrógeno total $(\mathrm{Nt})$ de $0.07 \%$. Las propiedades de estos suelos coinciden con los reportes que expresan de que los suelos del Altiplano Sur de Bolivia tienen textura gruesa con contenidos importantes de grava y el $\mathrm{N}$ está relacionada con la MO que es muy escaso. ${ }^{19,20}$

Preparación del terreno. Se realizó con arado de disco en un suelo que poseía un año de descanso, cada unidad experimental fue de $156 \mathrm{~m}^{2}$, las delimitaciones de las parcelas experimentales fueron marcadas con estacas de madera días antes de la siembra.

Siembra. Se implementó cuatro tratamientos (testigo $=\mathrm{T}_{1}$, estiércol de camélido $=\mathrm{T}_{2}$, extracto húmi$\mathrm{co}=\mathrm{T}_{3}$ y humita $15=\mathrm{T}_{4}$ ) con tres repeticiones. En la primera quincena del mes de septiembre en la campaña agrícola de 2014-2015. La siembra se realizó manualmente a una profundidad aproximado de 0.7 a $0.10 \mathrm{~m}$ con una distancia entre plantas y surcos de $1 \mathrm{~m}$. La semilla que se utilizó fue adquirida del productor de la zona.

Aplicación de enmiendas orgánicas. Se aplicaron una sola vez al suelo en el momento de la siembra de quinua. El estiércol de camélido fue adquirido de la zona y fue humedecido con agua a capacidad de campo y se aplicó a razón de $430 \mathrm{~kg} / \mathrm{ha}$ que equivale $43 \mathrm{~g}$ en cada golpe, el extracto húmico y humita 15 fue facilitado por el CIQ, éstas fueron diluidos con agua a razón de $20 \%$ y se aplicó a cada golpe alrededor de $20 \mathrm{~mL}$ de la solución preparada, lo que equivale a $40 \mathrm{~L} / \mathrm{ha}$. El factor de estudio fue las dife- rentes EO y se realizó bajo el diseño experimental de completamente al azar. ${ }^{21,22}$

Muestreo del suelo. Se recolectaron las muestras de cada unidad experimental en tres epocas en todo el ciclo fenológico del cultivo, la primera muestra fue despues de 30 dias de la siembra (15 de octubre), la segunda colecta fue en el mes lluvioso (15 de enero) y la ultima muestra fue cuando las quinuas llegaron al 50\% de madurez fisiologgica (15 de abril). De cada unidad experiemntal, se recolectaron tres muestras de suelo de la rizosfera de raíz de la quinua de una profundidad de 0.10 a $0.25 \mathrm{~m}$ en frascos estériles y fueron trasladadas inmeditamente al laboratorio del CIQ para su analisis correspondiente. ${ }^{23,24}$

Evaluación microbiana. Para cuantificar las colonias en las placas, las muestras de suelo se sometió a dilucion seriado. ${ }^{25}$ De las diluciones $10^{-3}$, $10^{-4}$ y $10^{-5}$ se tomaron $0.2 \mathrm{~mL}$ y se inoculó la primera dilución a cajas Petri con medio de cultivo solidificado de Agar Papa-Dextrosa (PDA) para hongos, la segunda dilución se transferió a las placas de Agar Glucosa de Extracto de Levadura (AGE) para actinomicetos y la ultima dilución fue para las bacterias, que se inoculó a las placas que contenian Agar Plate Count (APC), cada uno de ellos con tres repeticiones por muestra de suelo para después incubar a una temperatura de $25{ }^{\circ} \mathrm{C}$ para que formen colonias microbianas. Después de cinco dias se realizó el conteo de las colonias que se formaron en las placas con medio de cultivo especifico para cada grupo microbiana y fueron transformadas en Unidades Formadoras de Colonias (UFC) por gramo de suelo rizosferico. ${ }^{26,27}$ 


\section{Resultados}

Las poblaciones microbianas totales de la rizosfera del cultivo quinua en los cuatro tratamientos se observa que existe mayor formación de colonias en el mes de enero, superando a octubre y abril, se presume que en estos meses las poblaciones bajan por la escasez de la humedad en el suelo y por las temperaturas bajas que se presentan en estos meses, por otro lado, puede estar influyendo el tipo de suelo existente en la zona (figura 1).

Figura 1 Promedio de población total microbiana en UFC/g de suelo rizosférico de la raíz de quinua después de cinco días de incubación a una temperatura de $25^{\circ} \mathrm{C}$ : a) estiércol de camélido, b) extracto húmico, c) humita 15 y d) sin aplicación de EO (testigo)
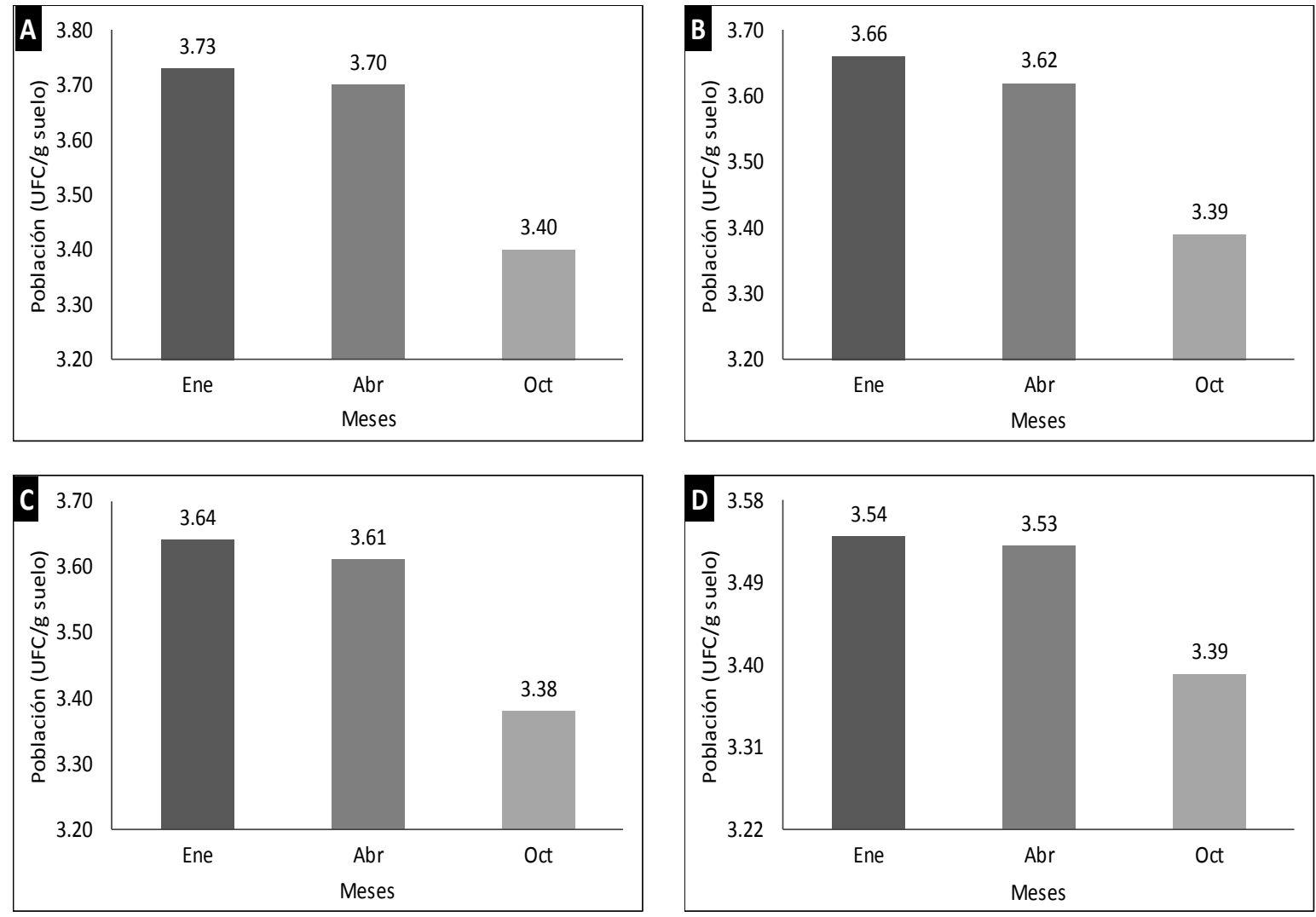

Los resultados del suelo rizosférico que fueron apliLos suelos que se muestrearon de la rizosfera de la quinua en diferentes meses y que éstos fueron analizados por método seriado, presentaron similaridad comportamiento en la población de actinomicetos, bacterias y hongos. Los tres grupos microbianas presentan mayor población en el mes de enero, donde existe mayor precipitación en la zona y no así en octubre y abril. Las bacterias siempre presentaron mayor número de colonias en las tres épocas de muestreo de suelo (figura 2). 
Tabla 2 Promedio de poblaciones de grupos microbianas de la rizosfera del cultivo de quinua en diferentes meses de muestreo de los suelos aplicados con diferentes EO

\begin{tabular}{|c|c|c|c|c|}
\hline Tratamientos & $\begin{array}{c}\text { Época de } \\
\text { muestreo } \\
\text { de suelo }\end{array}$ & $\underset{* 10^{5}}{\operatorname{Actinomicetos}}$ & $\begin{array}{c}\text { Bacterias } \\
*^{\mathbf{1 0}} \\
\text { UFC/g suelo } \\
\end{array}$ & $\begin{array}{l}\text { Hongos } \\
* \mathbf{1 0}^{4}\end{array}$ \\
\hline \multirow{3}{*}{ Estiércol } & Enero & $1.23 \mathrm{a}$ & $1.44 \mathrm{a}$ & $1.07 \mathrm{a}$ \\
\hline & Abril & $1.20 \mathrm{ab}$ & $1.43 \mathrm{a}$ & $1.06 \mathrm{a}$ \\
\hline & Octubre & $\begin{array}{l}1.14 \quad b \\
\rho=0.0320\end{array}$ & $\begin{array}{l}1.23 \quad b \\
\rho=0.0002\end{array}$ & $\begin{array}{l}1.03 \mathrm{a} \\
\rho=0.0723\end{array}$ \\
\hline \multirow{3}{*}{ Extracto húmico } & Enero & $1.19 \mathrm{a}$ & $1.41 \mathrm{a}$ & $1.06 \mathrm{a}$ \\
\hline & Abril & $1.17 \mathrm{a}$ & $1.40 \mathrm{a}$ & $1.05 \mathrm{a}$ \\
\hline & Octubre & $\begin{array}{l}1.13 \text { a } \\
\rho=0.5787\end{array}$ & $\begin{array}{l}1.23 \quad b \\
\rho=0.0023\end{array}$ & $\begin{array}{l}1.03 \mathrm{a} \\
\rho=0.1106\end{array}$ \\
\hline \multirow{3}{*}{ Humita 15} & Enero & $1.18 \mathrm{a}$ & $1.40 \mathrm{a}$ & $1.06 \mathrm{a}$ \\
\hline & Abril & $1.17 \mathrm{a}$ & $1.39 \mathrm{a}$ & $1.05 \mathrm{a}$ \\
\hline & Octubre & $\begin{array}{l}1.13 \text { a } \\
\rho=0.3150\end{array}$ & $\begin{array}{l}1.22 \quad b \\
\rho=0.0022\end{array}$ & $\begin{array}{l}1.03 \mathrm{a} \\
\rho=0.3170\end{array}$ \\
\hline \multirow{3}{*}{ Testigo } & Enero & $1.16 \mathrm{a}$ & $1.33 \mathrm{a}$ & $1.05 \mathrm{a}$ \\
\hline & Abril & $1.16 \mathrm{a}$ & $1.32 \mathrm{a}$ & $1.05 \mathrm{a}$ \\
\hline & Octubre & $\begin{array}{l}1.13 \mathrm{a} \\
\rho=0.8424\end{array}$ & $\begin{array}{l}1.22 \text { b } \\
\rho=0.0005\end{array}$ & $\begin{array}{l}1.03 \mathrm{a} \\
\rho=0.4219\end{array}$ \\
\hline
\end{tabular}

Figura 2 Comportamiento de la población microbiana ( $\mathrm{A}=$ actinomicetos; $\mathrm{B}=$ bacterias $\mathbf{y} \mathrm{H}=\mathbf{h o n g o s})$ en la rizosfera de la raíz de quinua en diferentes meses: a) estiércol de camélido, b) extracto húmico, c) humita 15 y d) sin aplicación de EO (testigo)
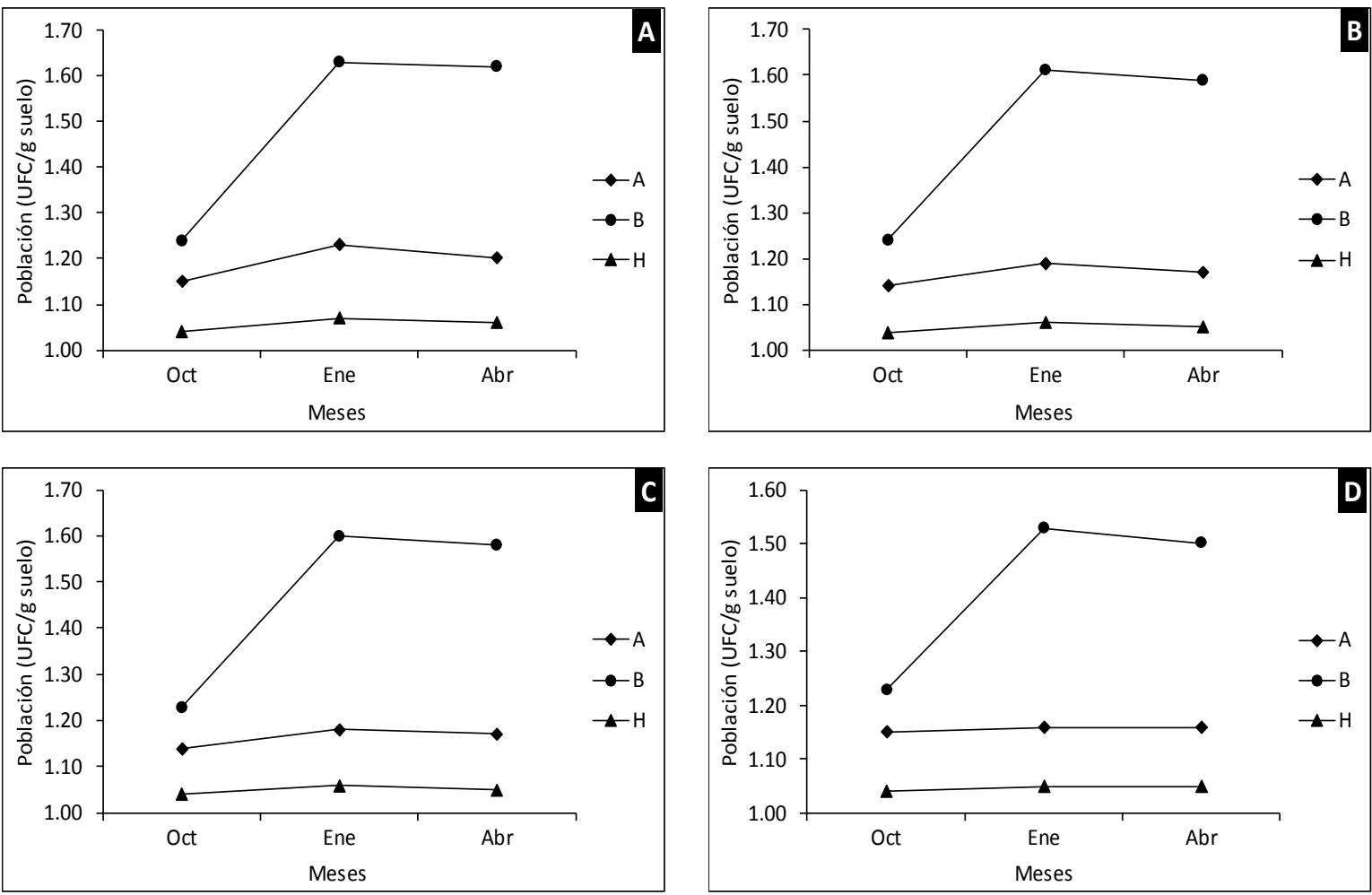

Se presume que los diferentes grupos microbianas y humedad existente en el suelo, ya que los diferenestán directamente relacionados con la temperatura tes suelos recolectadas en época donde la tempera- 
tura no desciende por debajo de $0{ }^{\circ} \mathrm{C}$ y la humedad esta a capacidad de campo, los diferentes tratamientos mostraron mayor formación de colonias en las placas, mientras que en los meses con escasez de humedad y donde las temperaturas están por debajo de $0{ }^{\circ} \mathrm{C}$ se observaron el descenso de los tres grupos microbianas.

\section{Discusión}

Cuantificación de población microbiana. El estudio comparativo de poblaciones microbianas con la aplicación de EO al suelo, expresa incremento en los tres grupos microbinos de la rizosfera de raíz de la quinua (figura 1) y su distribución de consorcios en climas fríos está altamente influenciada con el contenido de $\mathrm{MO}$, temperatura, humedad, $\mathrm{pH}$ y tipo de suelo. Los resultados concuerdan con las afirmaciones de que las comunidades microbianas asociadas a la rizosfera de las raíces de plantas tienen una actividad microbiana compleja ${ }^{28}$, procesos que contribuyen en el reciclado de los nutrimentos para las plantas. ${ }^{29,30}$

El suelo rizosférico de la quinua muestran heterogéneas comunidades microbianas, este puede estar directamente condicionado con el tipo de EO que se le aplicó al cultivo, ya que expresa cada tratamiento diferente colonización microbiana (figura 1), esto concuerda con las afirmaciones de que los altos niveles de nutrientes que se hallan en la zona que rodea a las raíces permiten el desarrollo de poblaciones microbianas $^{31}$ y se encuentra entre 0.5 a 0.15 $\mathrm{m}$ de profundidad ${ }^{32}$, pero mucho dependerá de la temporada, tipo de suelo, vegetación, contenido de humedad, tipo de labranza y fertilización ${ }^{33}$, donde cada especie en la rizosfera cumple un papel específico y se alimentan de metabolitos, hidratos de carbono y otros polímeros exudados por las raíces de cada planta. ${ }^{34-36}$ Los compuestos exudados por la raíz de la quinua y la EO aplicada contribuyen al incremento de las densidades poblacionales microbianas existentes en la rizosfera como en el suelo adyacente, pero cuando los macroagregados presentacen condiciones subóxicas podrían inhibir su actividad.

Las comunidades bacteriana y fúngica que se expresa en la rizosfera de las plantas aplicadas con estiércol de camélido, puede deber a la relación carbononitrógeno $(\mathrm{C} / \mathrm{N})$ y esto puede estar manifestandose en la expresión de cada grupo microbiano, este afirmación no concordaría con un estudio realizado en México en suelos volcánicos con sistemas de labranza cero, donde reportan que las comunidades bacteriana y fúngica presentan una estructura semejante en la rizósfera de Amaranthus hypochondriacus, Helianthus annuus, Zea mays y Cynodon dactylon $^{37}$, sin embargo, existen reportes que al alrededor de las raíces de las plantas en la llamada rizosfera es mucho mayor las poblaciones microbianas que en el resto del suelo ${ }^{38}$, en caso de las plantas de quinua, los exudados de sus raíces y el tipo de suelo pueden estar jugando un rol limitante en la expresion de los microorganismos.

Población de actinomicetos, bacterias y hongos. En los meses de enero y abril, el tratamiento con estiércol de camélido muestra similares poblaciones de actinomicetos con 1.23 y $1.20 \times 10^{5} \mathrm{UFC} / \mathrm{g}$ de suelo rizoférico respectivamente, pero en el mes de octubre expresa $1.14 \times 10^{5} \mathrm{UFC} / \mathrm{g}$ de suelo rizoférico, que es reducido, se presume que se debe a la poca humedad existente en el suelo y a las temperaturas bajas. Los de extracto húmico, humita 15 y testigo, ilustran poblaciones que estan entre 1.19 a $1.13 \times 10^{5}$ $\mathrm{UFC} / \mathrm{g}$ de suelo rizoférico, que no son diferentes estadísticamente entre los diferentes meses (tabla 2). Estos reultados se asemeja al comportamiento del suelo de banano (Musa sp.) en sistemas con manejo tradicional y orgánico, donde no reporta diferencias 
estadísticas en UFC de actinomicetos $^{39}$, pero no coincide con el tratamiento aplicado con estiércol de camélido en el presente trabajo, pero es atribuible que los actinomicetos son capaces de colonizar en el sistema de raíz de las plantas, debido a sus enzimas de celulasas y xilanasas que juegan un importante papel en la descomposición de MO y por tanto promueven el crecimiento de las plantas. ${ }^{40,41}$

Las bacterias en la rizosfera de la quinua en los meses de enero y abril expresan similitudes poblaciones de 1.44 a $1.43 \times 10^{6} \mathrm{UFC} / \mathrm{g}$ de suelo rizoférico en el ensayo con estiércol de camélido, extracto húmico que está entre 1.41 a $1.40 \times 10^{6} \mathrm{UFC} / \mathrm{g}$ de suelo rizoférico, humita 15 de 1.40 a $1.39 \times 10^{6}$ $\mathrm{UFC} / \mathrm{g}$ de suelo rizoférico y testigo de 1.33 a $1.32 \times 10^{6} \mathrm{UFC} / \mathrm{g}$ de suelo rizoférico, pero el mes de octubre en todos los tratamientos se ilustra una población reducida que va desde 1.23 a $1.22 \times 10^{6}$ UFC/g de suelo rizoférico (tabla 2). Estos resultados encontrados en la presente investigación concuerdan con las bacterias encontradas en suelos de Musa sp. en sistema orgánico y tradicional que reporta de 1.0 a $1.4 \times 10^{6} \mathrm{UFC} / \mathrm{g}$ de suelo, en una zona tropical de Bolivia $^{39}$, por otra parte, también coinciden con las afirmaciones de que las bacterias tienen un promedio de $10^{6}$ a $10^{9} \mathrm{UFC} / \mathrm{g}$ de suelo rizosférico y constituyen el grupo microbiano más numeroso. ${ }^{42-44}$

Los cuatro tratamientos expresan poblaciones de hongos similares que van de 1,07 a $1.03 \times 10^{4} \mathrm{UFC} / \mathrm{g}$ de suelo rizosférico en los diferentes meses, pero el de estiércol es relativamente superior a los de la humita 15 , extracto húmico y testigo (tabla 2), los resultados encontrados contrasta con los reportes de

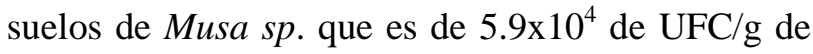
suelo $^{39}$, por otro lado, no existe similaridad con la afirmación de que los hongos asociadas a las rizosferas de plantas se encuentran entre $10^{5}$ a $10^{6} \mathrm{UFC} / \mathrm{g}$ de suelo ${ }^{45}$, y participan en numerosos procesos ecológicos, sanidad vegetal y crecimiento ${ }^{46}$, igualmente se observa que no existe similitud con los hongos encontrados en suelos de quinua del Altiplano Sur Boliviano, donde reportan diferencias significativas entre diferentes meses ${ }^{47}$, ni con afirmanes de que existe mayor población de hongos en suelos con presencia de cultivos. $^{48}$

Comportamiento microbiano en diferentes meses. Los tres grupos microbianas incrementan sus poblaciones a medida que mejora la temperatura y la humedad en el suelo por las precipitaciones existente en la zona, generalmente en mes de enero. Las bacterias son los más numerosos, seguido por actinomicetos y por último están los hongos. Por otro lado, los diferentes EO que fueron aplicadas, expresan mayor población microbiana frente a que no fueron aplicados (figura 2). Los resultados encontrados en la presente investigación concuerdan con las afirmaciones de que la incorporación de EO al suelo incrementa la población de biomasa microbia$\mathrm{na}^{49}$ y mejoran las propiedades físicas y químicas. ${ }^{50}$ El incremento de la humedad en el suelo aumenta su población, pero las bajas temperaturas afecta a su actividad normal $^{51}$, la fertilidad del suelo está controlada en gran medida por las actividades biogeoquímicas de la microbiota que actúa como abastecedor potencial de nutrientes para las plantas ${ }^{52}$, y los ácidos húmicos y fúlvicos estimulan la proliferación microflora del suelo. ${ }^{53,54}$

La EO tiene efectos favorables en el incremento de población microbiana y mejora su hábitat en la rizosfera de la raíz en suelos con mayor contenido de humedad y según el estado de desarrollo de las plantas de quinua.

La comunidad microbiana en la rizosfera presenta variación temporal y su población puede variar según las características propias del suelo y de su contenido en $\mathrm{MO}$, humedad, $\mathrm{pH}$ y de la temperatura, por otro lado, también influye el tipo de fertilización y el estado de la especie vegetal.

Las bacterias en la rizósfera se presentan con mayor población en comparación con actinomicetos y hon- 
gos, este comportamiento puede estar dado a su rápido crecimiento y a la habilidad de utilizar un amplio rango de sustratos como fuentes de nitrógeno o carbono.

La la poca humedad existente, las bajas temperaturas, el tipo de suelo y la escasez de la MO, resultó ser un factor limitante para los diferentes grupos microbianas existentes en la rizosfera puedan estimular el crecimiento de las plantas de quinua.

\section{Conflictos de intereses}

Los autores declaran que no tienen conflictos de interés con la presente investigación.

\section{Agradecimientos}

Se agradece a Dirección de Investigación Científica y Tecnológica (DICyT) de la Universidad Técnica de Oruro (UTO). A la Facultad de Ciencias Agrarias y Naturales (FCAN) y al Coordinador del Centro de Investigación de la Quinua (CIQ) por la facilitación del laboratorio.

Al laboratorio de suelos y aguas, Facultad de Ciencias Agrícolas y Pecuarias-Universidad Mayor de San Simón (UMSS), por la colaboración en el análisis de los suelos.

\section{Aspectos Éticos}

Todos los aspectos procedimentales experimentales fueron aprobados por el Comité de ética del Dirección de Investigación Científica y Tecnológica (DICyT) de la Universidad Técnica de Oruro (UTO).

\section{Literatura Citada}

1. Nogales Fernández B. La microbiología del suelo en la era de la biología molecular: des- cubriendo la punta del iceberg. Ecosistemas. 2005;14(2):41-51.

2. Paul EA, Clark FE. Soil microbiology and biochemistry. Academic Press, Inc. San Diego. California; 1989. $254 \mathrm{p}$.

3. Coyne M. Microbiología del suelo: un enfoque exploratorio. En: Thomson-Paraninfo. ITPAN International Thomson Publishing Company. Madrid-España; 2000. 416 p.

4. Pool Novelo LA, Trinidad Santos J, Etchevers Barra J, Pérez Moreno A, Martínez Garza. Mejoradores de la fertilidad del suelo en la agricultura de ladera de los altos de Chiapas. México. Agrociencia. 2000;34(3):251-59.

5. He Z, Zhang H. Applied manure and nutrient chemistry for sustainable agriculture and environment. Springer, London; 2014. 373 p. DOI: https://dx.doi.org/10.1007/978-94-017-8807-6

6. Abbasi MK, Khizar A. Microbial biomass carbón and nitrogen transformations in a loam soil amended with organic-inorganic $\mathrm{N}$ sources and their effect on growth and $\mathrm{N}$-uptake in maize. Ecol Eng. 2012;39:123-32. DOI: https://dx.doi. org/10.1016/j.ecoleng.2011.12.027

7. Gilly JE, Eghball B. Residual effects of compost and fertilizer applications on nutrients in runoff. Amer Soc Agric Biol Eng. 2002;45:1905-10. https://dx.doi. org/10.13031/2013.11441

8. Lynch JM. Beneficial interactions between micro-organisms and roots. Biotech Adv. 1990; 8(2):335-46. DOI: https://doi.org/10.1016/07349750(90)91069-S

9. Glick BR. The enhancement of plant growth by freeliving bacteria. Can J Microbiol. 1995; 41(2):109-17. DOI: https://dx.doi.org/10.1139/ m95-015

10.Gutiérrez Mañero FJ, Ramos-Solano B, Probanza A, Mehouachi J, Tadeo FR, Talon M. The plantgrowth promoting rhizobacteria Bacillus pumilus 
and Bacillus licheniformis produce high amounts of physiologically active gibberellins. Physiol Plant. 2001;111(2):206-11. DOI: https://dx. doi. org/10.1034/j.1399-3054.2001.1110211.x

11.Richardson AE, Barea JM, McNeill AM, Prigent Combaret C. Acquisition of phosphorus and nitrogen in the rhizosphere and plant growth promotion by microorganisms. Plant Soil. 2009; 321(1-2):305-39. DOI: https://dx.doi.org/10.1007 /s11104-009-9895-2

12.Barea JM, Azcón R, Azcón Aguilar C. Interactions between mycorrhizal fungi and bacteria to improve plant nutrient cycling and soil structure. En: Buscot F, Varma A (eds.). Microorganisms in soils: roles in genesis and functions. SpringerVerlag, Berlin; 2005. p. 195-212. DOI: https://dx. doi.org/10.1007/3-540-26609-7 10

13.Bazile D, Bertero D, Nieto C, (Editores). Estado del arte de la quinua en el mundo en 2013: FAO (Santiago de Chile) y CIRAD, (Montpellier, Francia); 2014. 724 p.

14. Organización de las naciones unidas para la agricultura y la alimentación. La Quinua: Cultivo milenario para contribuir a la seguridad alimentaria mundial; 2011.49 p.

15.Rojas W, Soto JL, Carrasco E. Estudio de los impactos sociales, ambientales y económicos de la promoción de la quinua en Bolivia [Internet]. La Paz: Fundación PROINPA; 2004 [citado 22de octubre de 2018]. 82 p. Recuperdo a partir de: http://www.underutilized-species.org/Documen ts/PUBLICATIONS/quinoa_case_study_es.pdf

16.Jacobsen SE. The situation for quinoa and its production in southern Bolivia: From economic success to environmental disaster. J Agron Crop Sci. 2011;197(5):390-99. DOI: https://dx.doi.org/ 10.1111/j.1439-037X.2011.00475.x

17. Vallejos Mamani PR, Navarro Fuentes Z, Ayaviri Nina D. Medio ambiente y producción de la quinua. Estrategias de adaptación a los impactos del cambio climático [Internet]. La Paz: Programa de Investigación Estratégica en Bolivia; 2011 [citado 22-de octubre de 2018]. 241 p. Recuperdo a partir de: https://www.worldcat.org/title/medioambiente-y-produccion-de-quinua-estrategias-deadaptacion-a-los-impactos-del-cambio-climatico loclc/793843173

18.Aroni JC, María Cayoja M, Laime MA. Educación para el desarrollo. Situación actual al 2008 de la Quinua Real en el Altiplano Sur de Bolivia. 1ra Edición. Oruro-Potosí-Bolivia; 2009. 165 p.

19. Orsag Céspedes V, Mamani Reynoso F, Castro Ramos E, León Patzi ML, Pacosaca Yana O. Programa de investigación estratégica en Bolivia. Evaluación de la fertilidad de los suelos en la zona intersalar. Producción sostenible de la quinua. La Paz-Bolivia. Editorial Mauricio Murillo; 2011. $173 \mathrm{p}$.

20.Michel AJ, Weeda A, Villarroel G, Rocca J, Villarroel F, Flores I et al. Fundación para el desarrollo. Estudio de suelos del área productora de quinua real. Altiplano Sur Boliviano. Informe final. Sucre-Bolivia; 2008. 152 p.

21.Pedroza H. Fundamentos de la experimentación agrícola. Centro de Estudios de Ecodesarrollo para el Trópico. Managua-Nicaragua. Editorial Arte; 1993. p. 73-81.

22.Fernández Escobar R, Trapero Casas A, Domínguez Jiménez J. Experimentación en agricultura [Internet]. Córdoba-España: Ed. Junta de Andalucía. Consejería de agricultura y pesca; 2010 [citado 22-de octubre de 2018]. p. 85-56. Recuperado a partir de: https://www.juntadeanda lucia.es/export/drupaljda/1337160941EXPERIME NTACION.pdf

23. Organización de las naciones unidas para la agricultura y la alimentación. Guía para la descripción de suelos [Internet]. Roma-Italia: (Trad. R. Vargas). 4ta ed; 2009 [citado 22-de octubre de 
2018]. p. 66-67. Recuperado a partir de: http:// www.fao.org/3/a-a0541s.pdf

24.Bautista Zúñiga F, Delfín González H, Palacio Prieto JL, Delgado Carranza MD. Técnicas de muestreo para manejadores de recursos naturales. Centro de investigación en Geografía Ambiental. Universidad Nacional Autónoma de México. 2a ed; 2011 [citado 22-de octubre de 2018]. p. 299237. Recuperado a partir de: http://www. ciga. unam.mx/publicaciones/images/abook_file/tmues treo.pdf

25.Sánchez MJ. Microbiología de suelos. Técnicas, métodos y medios de cultivo. Facultad de Estudios Superiores Zaragoza. Universidad Nacional Autónoma de México; 2004 [citado 22-de octubre de 2018]. p. 5-36 Recuperado a partir de: file:///C:/Users/NXT/Downloads/Microbiologia\%2 0de\%20suelos.pdf

26.Guzman Estrada AE. Aislamiento y caracterización de bacterias solubilizadoras de fósforo a partir de cuatro suelos de la provincia de Chimborazo [Tesis Licenciatura]. [Riobamba]. Escuela Ingeniería Agronómica. Riobamba, Ecuador; 2011. 45 p. Recuperado a partir de: http://dspace. espoch.edu.ec/handle/123456789/1827

27.Beltran Pineda ML, Rocha Gil ZE, Bernal Figueroa. Microorganismos funcionales en suelos con y sin revegetación en el municipio de Villa de Leyva, Boyacá. Colombia Forestal. 2017; 20(2):158-70. DOI: http://dx.doi.org/10.14483/ udistrital.jour.colomb,for,2017.2.a05

28.Landi L, Valori F, Ascher J, Renella G, Falchini L, Nannipieriet P. Root exudate effects on the bacterial communities, $\mathrm{CO}_{2}$ evolution, nitrogen transformations and ATP content of rhizosphere and bulk soils. Soil Biol Biochem. 2006; 38(3):509-16. DOI: https://dx.doi.org/10.1016/j. soilbio.2005.05.021
29.Nannipieri P, Ascher J, Ceccherini MT, Landi L, Pietramellara G, Renella G. Microbial diversity and soil functions. Eur J Soil Sci. 2003;54:65570. DOI: https://dx.doi.org/10.1046/j.1351-0754. 2003.0556.x

30.De Deyn GB, Raaijmakers CE, Van Der Putten WH. Plant community development is affected by nutrients and soil biota. J Ecol. 2004; 92(5):824-34. DOI: https://dx.doi.org/10.1111 /j.0022-0477.2004.00924.x

31. Glick BR. The enhancement of plant growth by freeliving bacteria. Can J Microbiol. 1995; 41(2):109-17. DOI: https://dx.doi.org/10.1139/ m95-015

32. Sutherland IW. Structure-function relationships in microbial exopolysaccharides. Biotech Adv. 1994;12(2):393-448. DOI: https://dx.doi.org/ 10.1016/0734-9750(94)90018-3

33. Killian M, Steiner U, Krebs B, Junge H, Schmiedeknecht G, Hain R. FZB24 Bacillus subtilis-mode of action of a microbial agent enhancing plant vitality. Pflanzenschut-Nachrichten Bayer. 2000;53(1): 72-93.

34.Lesuffleur F, Paynel F, Bataillé MP, Le Deunff E, Cliquet JB. Root amino acid exudation: measurement of high efflux rates of glycine and serine from six different plant species. Plant Soil. 2007; 294(1-2):235-46. DOI: https://dx.doi.org/10.1007 /s11104-007-9249-x

35. Schimel JP, Weintraub MN. The implications of exoenzyme activity on microbial carbon and nitrogen limitation in soil: a theoretical model. Soil Biol Biochem. 2002;35:549-63. DOI: https://ex. doi.org/10.1016/S0038-0717(03)00015-4

36. Caldwell BA. Enzyme activities as a component of soil biodiversity: A review. Pedobiologia. 2005;49(6):637-44. DOI: https://dx.doi.org/10. 1016/j.pedobi.2005.06.003 
37.Moreno Espíndola IP, Ros M, De León González F, Ferrara Guerrero MJ, Rivera Becerril F, González Halphen D et al. El papel de las raíces y la microbiota en la estabilidad y fertilidad de suelos volcánico-arenosos del Valle de México. Sociedades Rurales, Producción y Medio Ambiente. 2010;10:18-37.

38.Cardon ZG. Whitbeck JL. The rhizosphere. An Ecological Perspective. Elsevier Academic Press. San Diego, California. USA; 2007. 201 p.

39. Toro Moreira T. Evaluación poblacional de microorganismos en suelos con manejo orgánico y tradicional de banano (Musa sp.) en Porvenir, La Paz [Tesis Licenciatura]. [La Paz]: Universidad Mayor de San Andrés. La Paz, Bolivia; 2005. 98 p. Recuperado a partir de: http://hdl. handle.net/123456789/5243

40.Carla da Silva Sousa CS, Fermino Soares AC, Garrido MS. Characterization of Streptomyces with potential to promote plant growth and biocontrol. Sci Agric. 2008;65(1):50-55. DOI: http://dx.doi.org/10.1590/S0103-90162008000 100007

41.Zhou Q, Li K, Jun X, Bo L. Role and functions of benefical microorganisms in sustainable aquaculture. Bioresour Technol. 2009;100(16):3780-86. DOI: https://dx.doi.org/10.1016/j.biortech.2008. 12.037

42.Jurkevithc E, Hadar Y, Chen Y. Differential siderophore utilization and iron uptake by soil and rhizosphere bacteria. Appl Environ Microbiol. 1992;58(1):119-24.

43. Cabrera G, Crespo G. Influencia de la biota edáfica en la fertilidad de los suelos en ecosistemas de pastizales. Revista cubana de ciencia agrícola. 2001;35(1):3-4.

44.Fernández MC, De Oliveira M, LC. Fauna de Solo: Aspectos Gerais e Metodológicos. Empresa Brasileira de Pesquisa Agropecuária Agro biolo- gia. Ministério da Agricultura e do Abastecimento; 2000: 112.

45.Sylvia D, Fuhrmann J, Hartel P, Zuberer D. Principles and Applications of Soil Microbiology. Pearson Education. New Jersey; 2005. 640 p.

46.Hawksworth DL, Rosmann AY. Where are all the undescribed fungi?. Phytopathology. 1997; 87(9):888-891. DOI: https://dx.doi.org/10.1094/ phyto.1997.87.9.888

47.Paco Pérez V. Loza Murguia MG, Vino Nina L, Calani Bueno E, Serrano Canaviri T. Población fúngica en suelos productores de quinua (Chenopodium quinoa Will.), bajo diferentes sistemas de manejo en la comunidad de Kerecaya municipio de Salinas de Garci Mendoza. J Selva Andina Res Soc. 2017; 8(1):26-47.

48.Pacasa Quisbert F, Loza Murguía MG, Bonifacio Flores A, Vino Nina L, Serrano Canaviri T. Análisis a la comunidad de hongos filamentosos en suelos del agroecosistema de K'iphak'iphani, comunidad Choquenaira-Viacha. J Selva Andina Res Soc. 2017;8(1):2-25.

49.Álvarez Solís JD, Díaz Pérez E, León Martínez NS, Guillén Velásquez J. Enmiendas orgánicas y actividad metabólica del suelo en el rendimiento de maíz. Terra Latinoam. 2010;28(3):239-45.

50.Delgado Londoño DM. Aplicación de enmiendas orgánicas para la recuperación de propiedades físicas del suelo asociadas a la erosión hídrica. Lámpsakos. 2017;17:77-82. DOI: http://dx.doi. org/10.21501/21454086.1907

51.Ramos Vásquez E, Zúñiga Dávila D. Efecto de la humedad, temperatura y $\mathrm{pH}$ del suelo en la actividad microbiana a nivel de laboratorio. Ecología Aplicada. 2008;7(1-2):123-30.

52. Sivila de Cary, R, Angulo W. Efecto del descanso agrícola sobre la microbiota del suelo (Patarani - Altiplano Central boliviano). Ecología en Bolivia. 2006;41(3):103-15. 
53.Senesi N, Miano TM, Provenza MR, Brunetti G. Characterization, differentiation and classification of humic substances by fluorescence spectroscopy. Soil Sci. 1991;152(4):259-271. DOI: http://ww.dx.doi.org/10.1097/00010694-1991100 00-00004
54.Aganga AA, Tshwenyane SO. Lucerne, lablab and Leucaena leucocephala forages: Production and utilization for livestock production. Pak J Nutr. 2003;2(2):46-53. DOI:

https://dx.doi.org/10.3923/pjn.2003.46.53 